\title{
مسجد فاتحية بمدينة يانيه "يانينا" بشمال اليونان دراسة أثرية معمارية
}

أ.د/عحم حمزة إسماعيل الحداد أ.د/أحمد أمين أ.آيه عبد العزيز إبراهيم

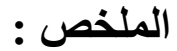

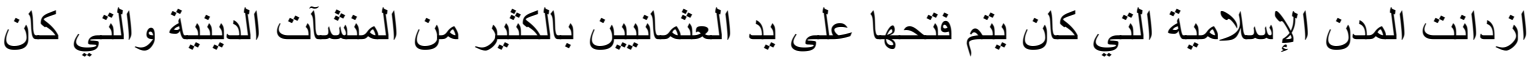

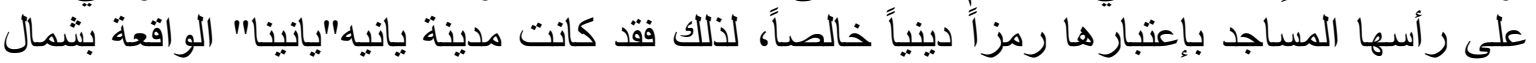
اليونان واحدة من تلك المدن التي زينها العثمانيون بمجمو عة كبيرة من المساجد ذات المآذن الثـاهقة،

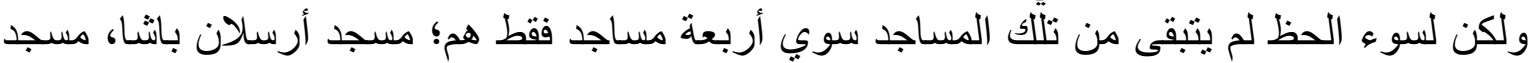

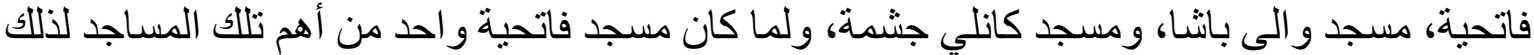
وقع الاختيار على تقديمه في هذا البحثة ومثئ.

في هذا البحث سوف يتم إلقاء الضوء على الوصف المعماري للمسجد وشرح وتفصيل مفرداته المعمارية، بالإضافة لتحليل الطر از المعماري الذي خضع له تخطيط هذا المسجد وتأصيله.

الكلمات الالة: اليونان، مدينة يانيه"يانينا"، مسجد فاتحية، على باشا، قبة

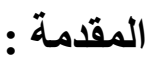

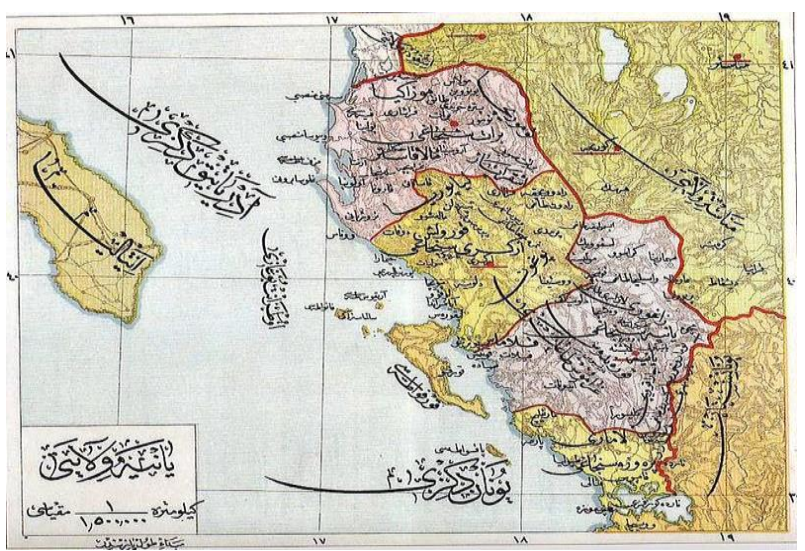

خريطة عثمانية لمدينة يانيه"يانينا"عام V.9.

https://www.wikiwand.com/en/Sanjak_of_Preveza

مدينة يانيه "يو انينا" هي عاصمة إقليم إيبيروس ا وهي واحدة من أهم المر اكز التجاريةب و الثقافية

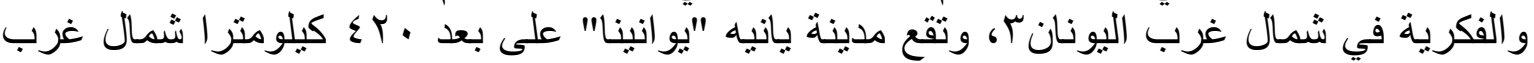
أثنيا و ، ب Y كيلومترا جنوب غرب سالونيكء، وتقع المدينة تحديدا على الضفة الغربية من بحيرة بامفوتيدا (Pamvotis)

من الجدير بالذكر أنه في الوقت الحالي لم يعد يقبل الرأي السائد سابقا بأن المدينة قام بتأسيسها

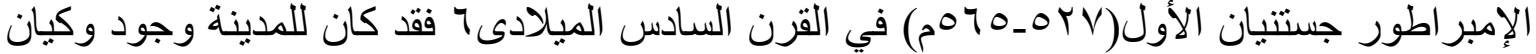
قبل ذلك التاريخ V، حيث كانت مدينة يانيه "يانينا" واحدة من أهم المدن التابعة لمنطقة إيبيروس خلانل العصور الوسطي. 


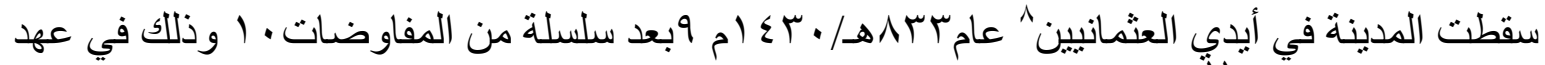

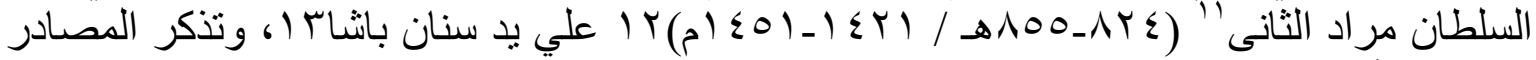

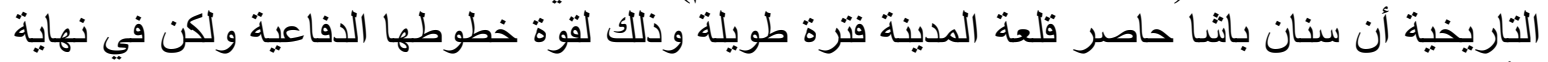

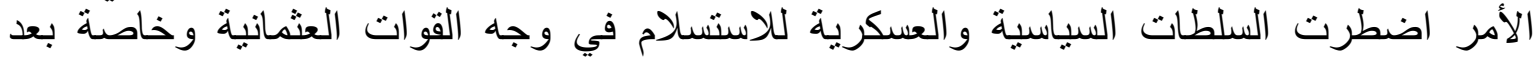
معرفتهم بالكارثة التي أطاحت بسالونيك في نفس العام، وقام العثمانيون بعمل عهد الأهل المديكة المدينة يحفظ لهح جميع الامتياز ات السابقة وتم منح السكان إعفاءات ضريبية, أعطاهم حرية التجارة وحصانة وحسانة من

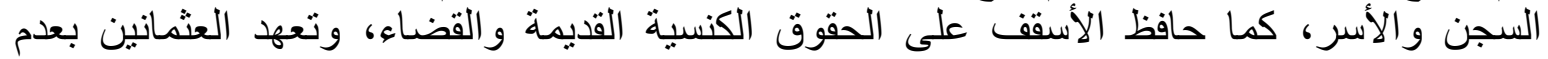

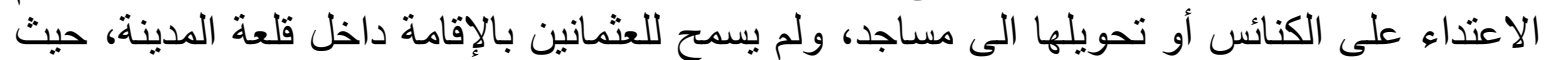

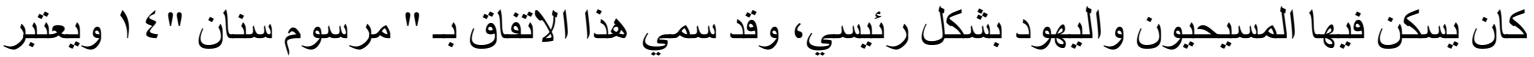
هذا المرسوم من أو ائل الوثائق العثمانية باليونان.

وخلال فترة القرن | (اهـ/V ام ظهرت كثير من حركات التمرد على الدولة العثمانية أهمها كانت عام

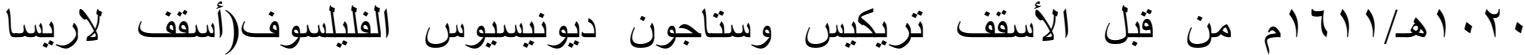
(Larissa

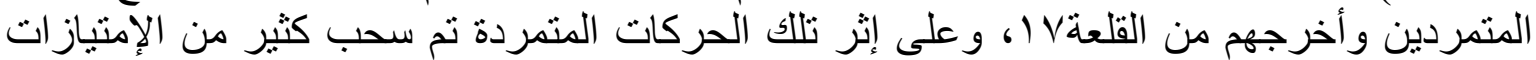

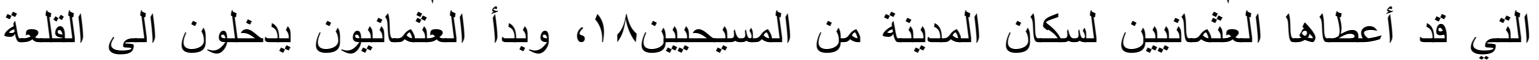

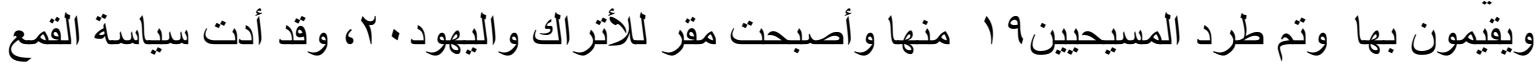

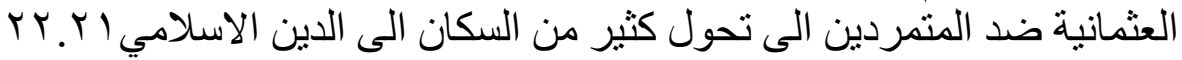

ومنذ أن استوطن العثمانيون قلعة المدينة شر عو الفي بناء المساجد و المؤسسات الدينية المحتلفة لإقامة

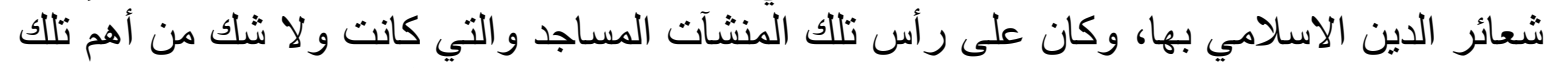
المؤسسات التى كان يحرص المسلمون بصفه عامة على إقامتها في المدن الجديدة التي يتم فتحها حيث تعد رمزاً للدين الاسلامي. تاني.

\section{موضوع البحث:}

يعتبر مسجد على باثـا من أهم تللك المساجد التي أقامها العثمانيون داخل قلعة مدينة يانيه"يانينا" حيث كان على باثنا حاكما للمدينة في فترة تو اجد العثمانيون بها.

بعتبر المسجد نواة لمجمع دينى كبير يضم مدرسة دينية و أماكن لسكن الطلاب بالإضافة إلي تربة

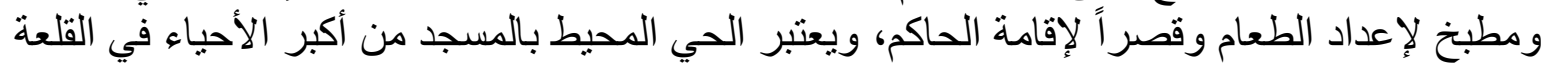

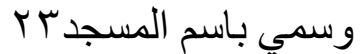

أولاً: الار اسة الوصفية للمسجد:-

موقع المسجد:

يقع مسجد فاتحية أو كما يقال ( مسجد الفاتح ) أو مسجد كابلان باثاء ب في الجهة الجنوبية الثرقية من قلعة المدينةه ب، وقد بنى على أعلى نقطة داخل قلعة مدينة يانيه"يانينا"، بالقرب من فن المتحف

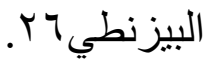
يأتي اسم فاتحية من الكلمة التركية (Fatih) و التي تعنى الفاتح و اللاحقة (ye) تعنى له. YV 
منشئ المسجد:

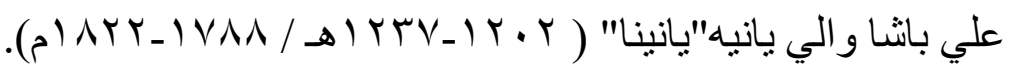

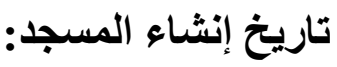

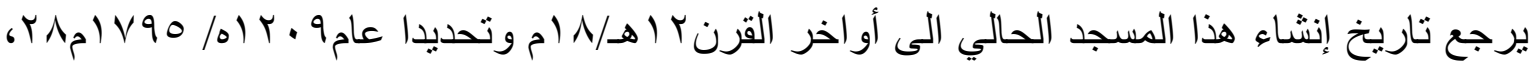

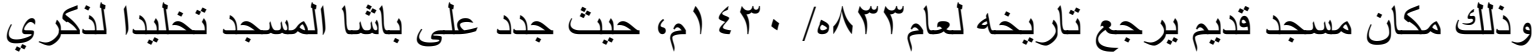

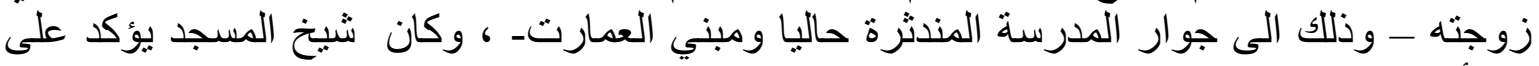
هذا أثناء دعائه لعلى باثنا.

الوصف المعماري للمسجد:

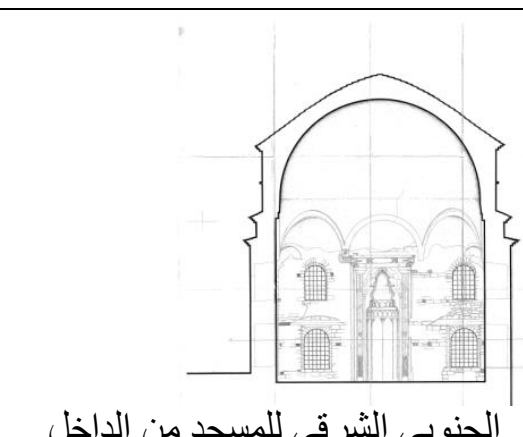

قطاع للجدار الجنوبي الثرقي للمسجد من الداخل

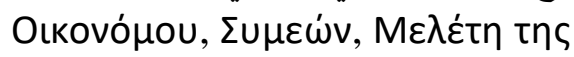

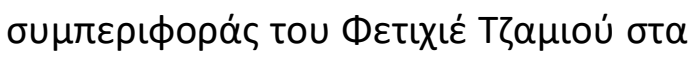

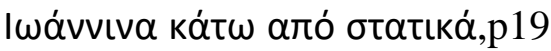

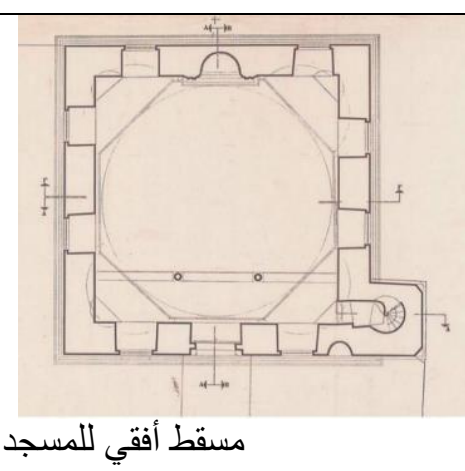

ÖZTUĞ, Ela Umut, YANYA MERKEZ OSMANLI MIMARIS, ,s107

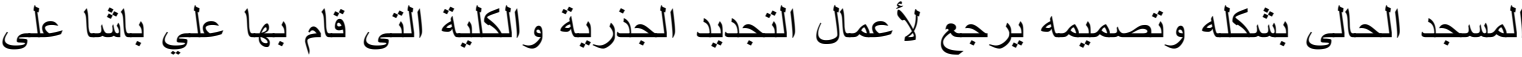

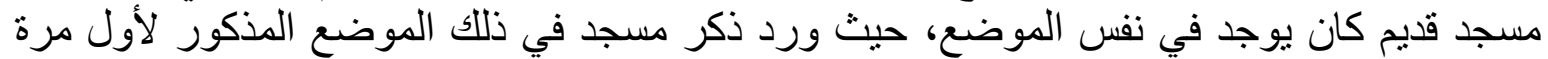

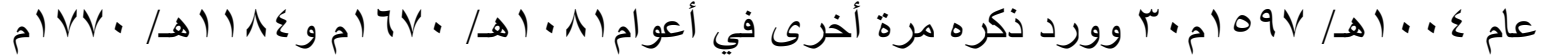

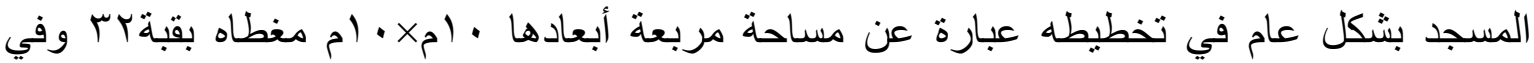

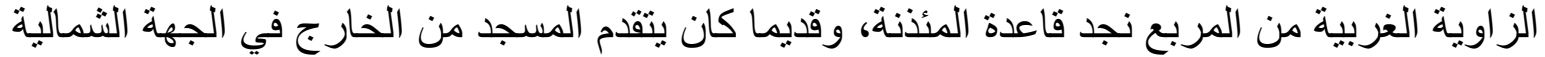

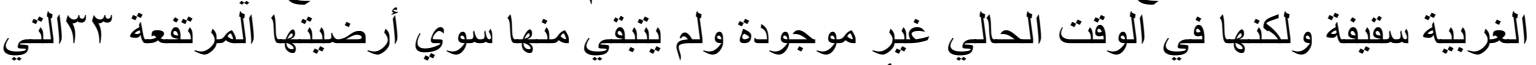

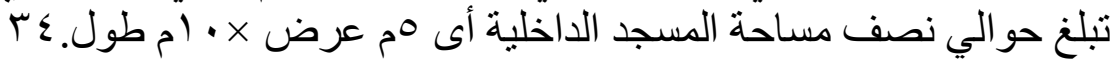
وبعد إجلاء الحكم العثماني عن مدينة يانيه"يانينا" عام سا 9 أم تحول المسجد الى مستشفي عسكري

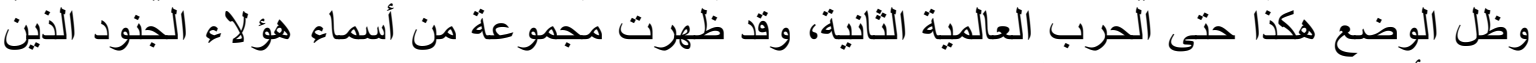
حفروا أسمائهم باللغة اليونانية على جدر ان المسجد. 


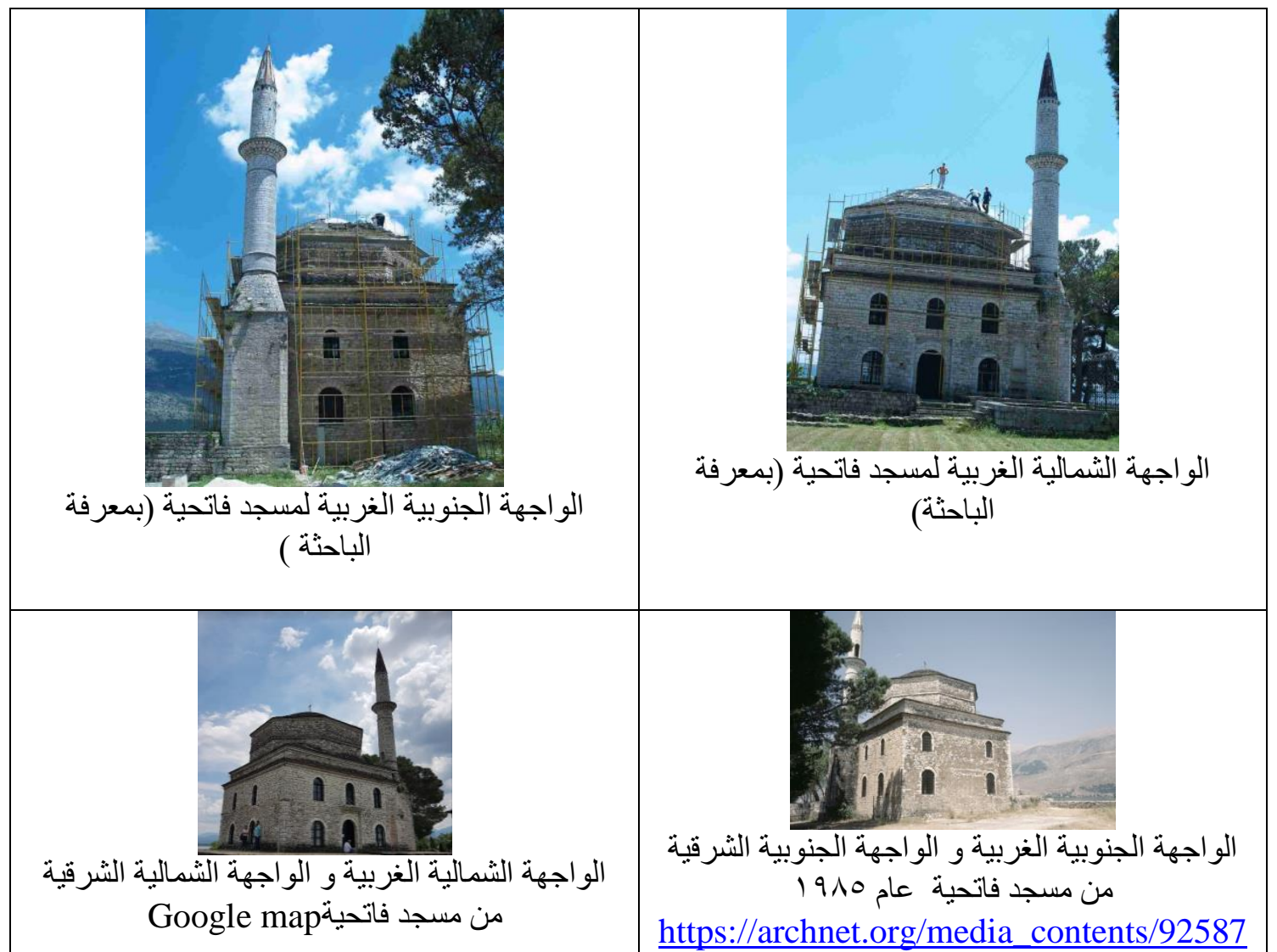

بسبب عدم إستواء الأرض التي بني عليه المسجد نجد أن كل من الواجهة الثمالية الغربية و الواجهة

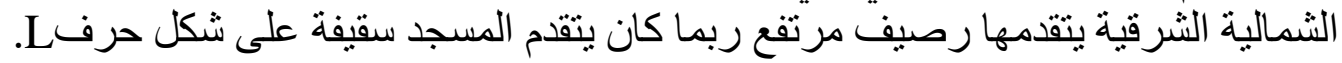

الواجهة الثمالية الغربية للمسجدهي الواجهة الرئيسية للمسجد ويوجد بها المدخل الرئيسي المؤدي الي

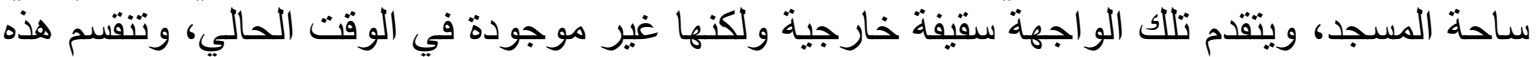

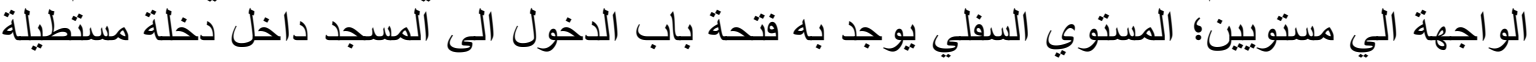

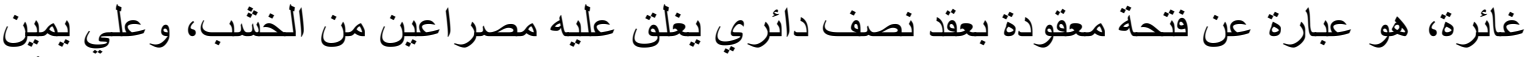

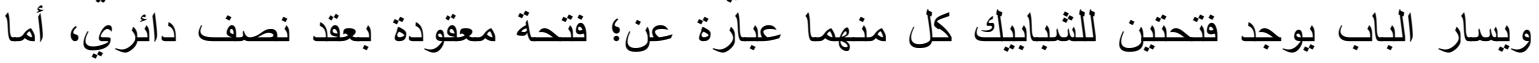

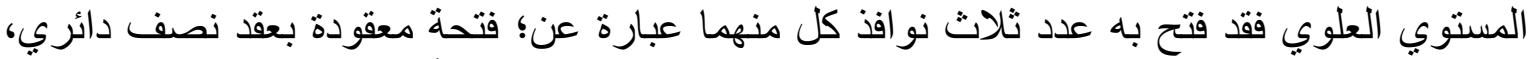

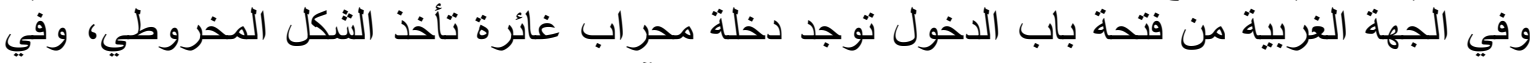

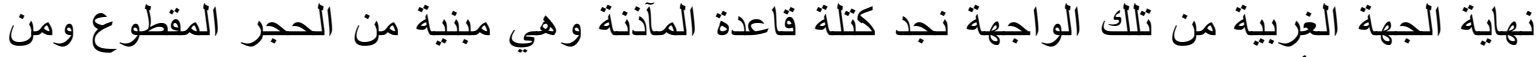

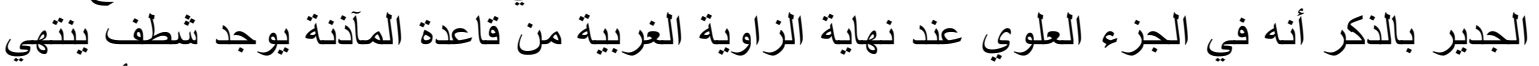

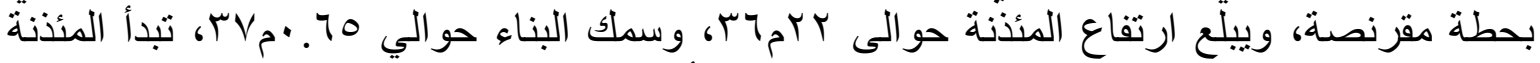

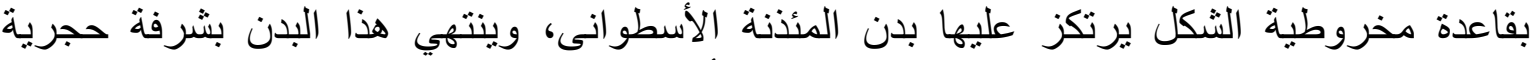

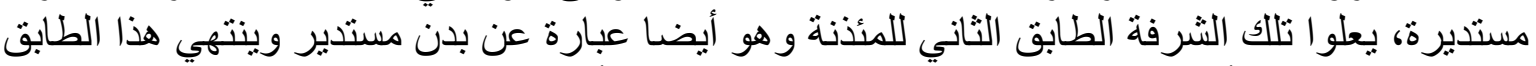

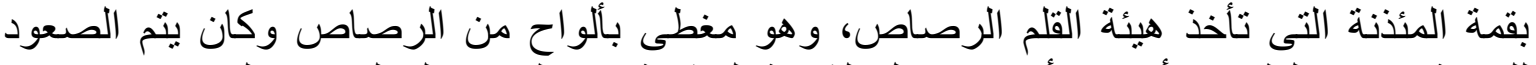

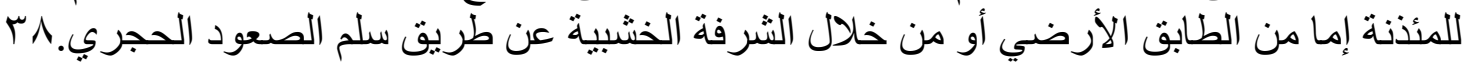
وتزدان قاعدة المئذنة بمجموعة من أربع لوحات حجرية منحوتة وتحديدا في الناحية الغربية للمئذنة،

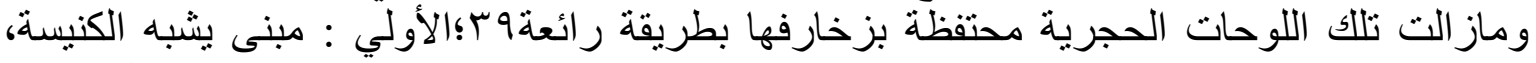
و هي ترمز للدين المسيحي،الثانية رمز فيثاغورس للتصوف الدينى الذي علمه موسي على جبل سين سيناء؛ 
و هذا الرمز إثارة للايانة اليهودية، الثالثة صورة زهرة وهي ترمز للايانة البوذية، الرابعة :صورة

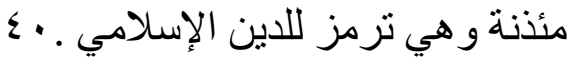

الو اجهة الجنوبية الغربية للمسجد، تبدأ تللك الو اجهة من الجهة الغربية بقاعدة المئننة ثم ترتد الى الداخل

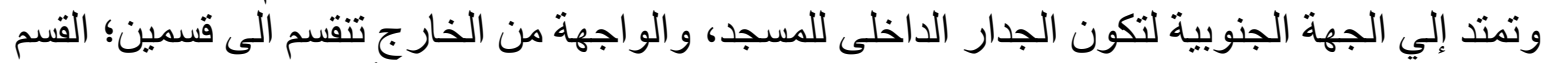

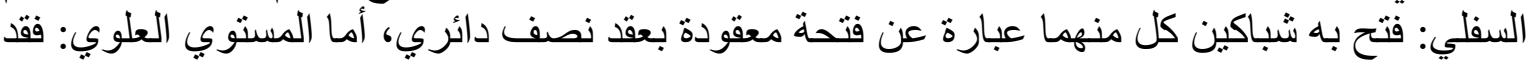
فتح به عدد ثلاث نو افذ كل منهما عبارة عن فتحة معقودة بعقد نصفي نصف دائري.

الواجهة الجنوبية الثرقية للمسجد وتتثابه مع الواجهة الجنوبية الغربية حيث أنها تنقسم الى قسمين؛

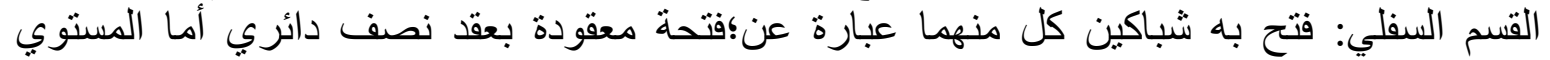

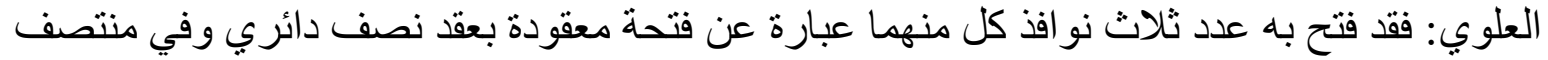

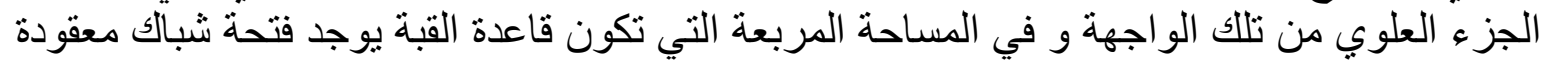
بعقد نصف دائري، و هذه النافذة من الداخل تعلو تجويف الدحر ابعاب.

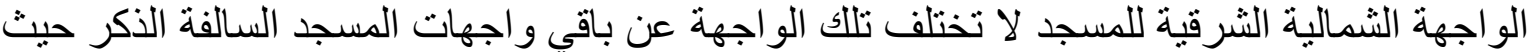

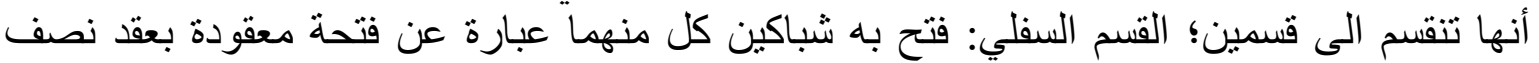

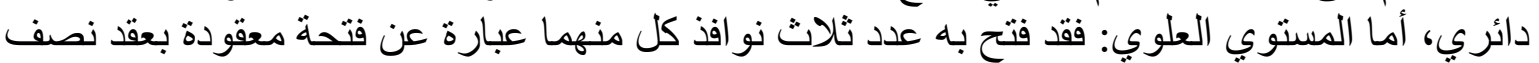

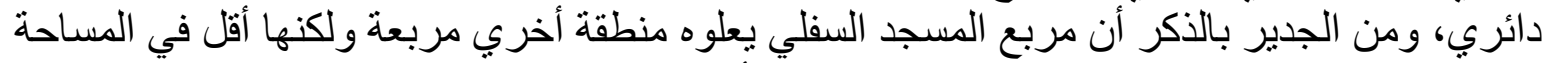

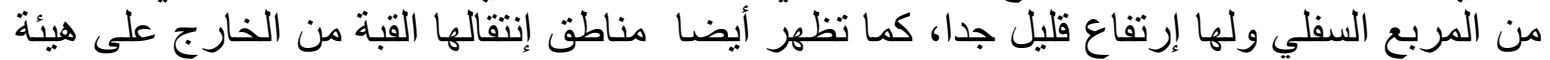

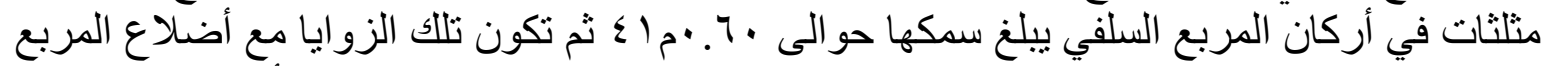

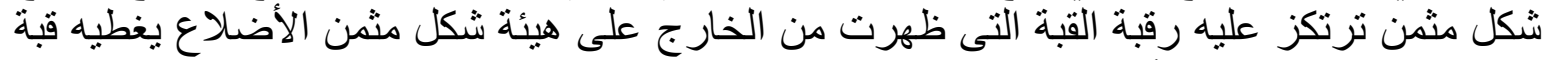

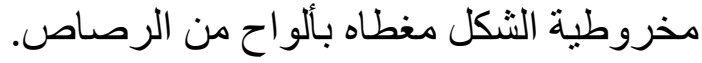

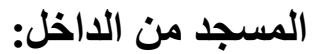

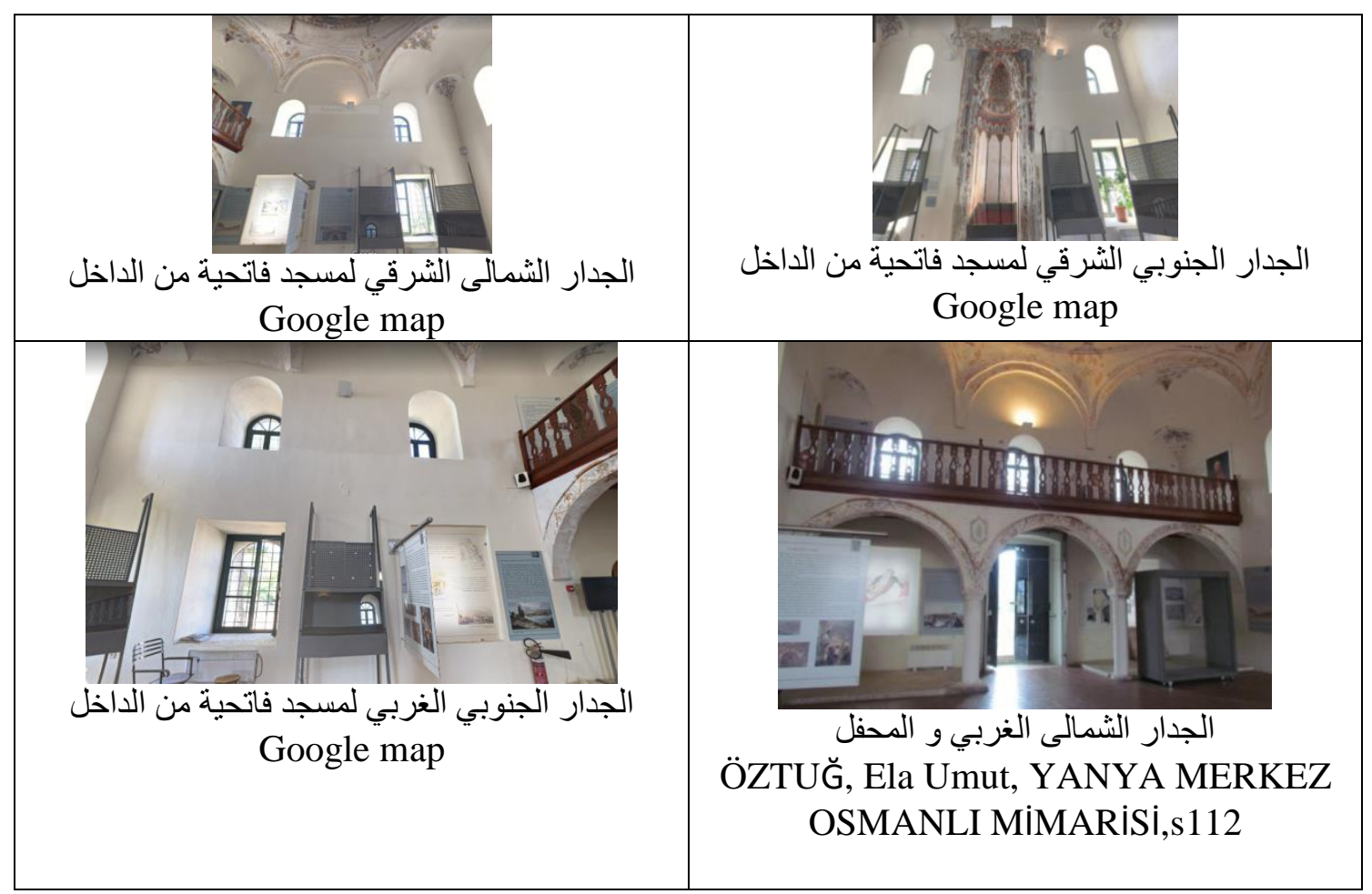


المسجد من الداخل أو ما بطلق عليه ساحة الصلاة عبارة عن مساحة مربعة مغطاه بقبة محمولة على القي حنايا ركنية، وقد زينت جدران المسجد من الداخل بمجوعة كبيرة من الزخارف النباتية و الهندسية

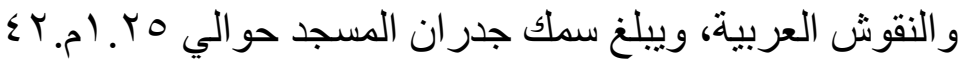

الجدار الجنوبي الثرقي (جدار القبلة) للمسجد من الداخل؛ يتوسطه كتلة المحر اب، وعن يمين ويسار

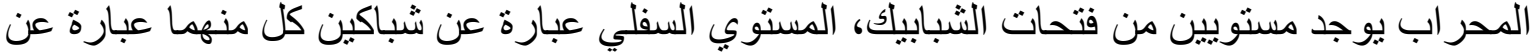

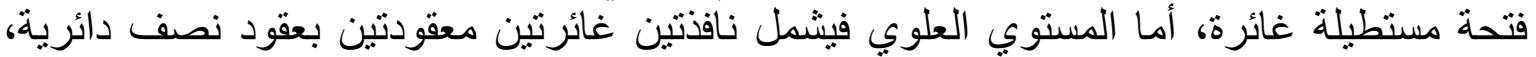

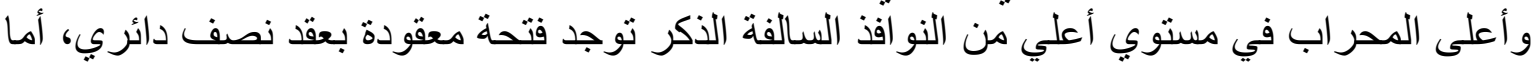

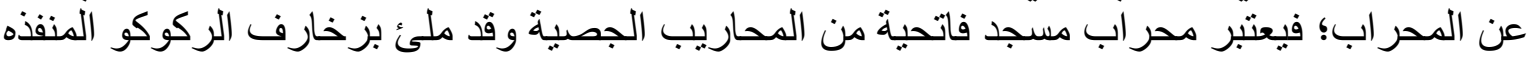
بالألوان المائية على الجص، وهو عبارة عن حنية نصف دائرية معقودة من أعلي بعقد متعدد

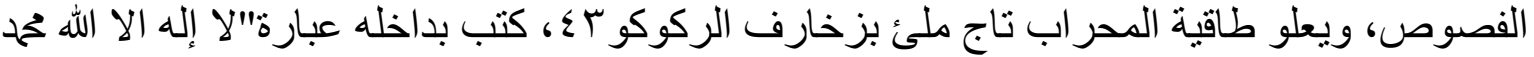

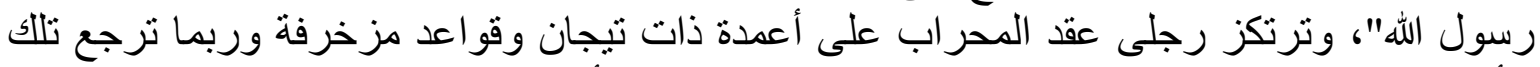

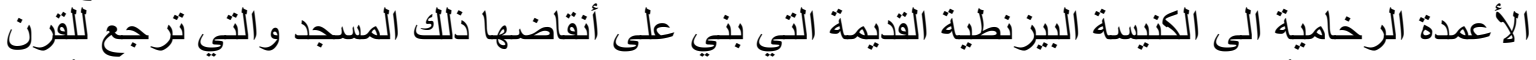

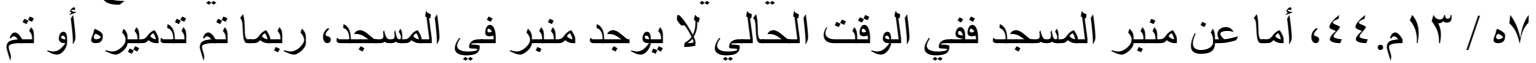
نقله.

الجدار الجنوبي الغربي للمسجد من الداخل يشتمل علي شباكين سفليين كل منهما عبارة عن فتحة

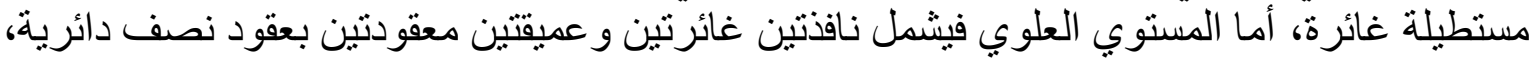

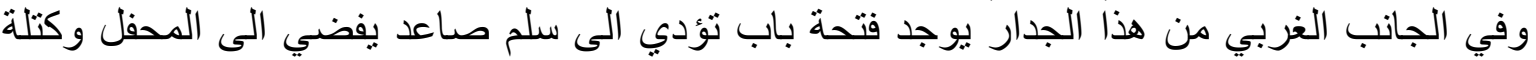

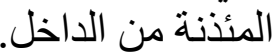

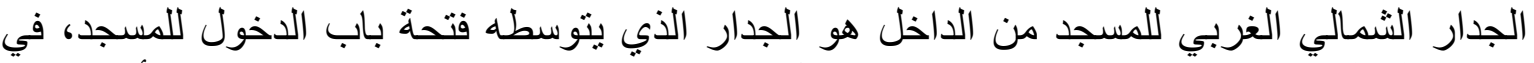

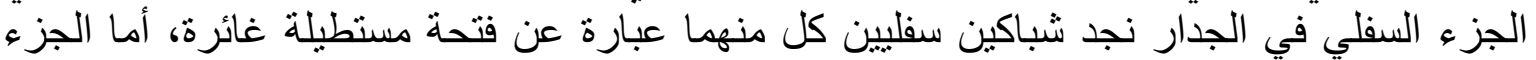

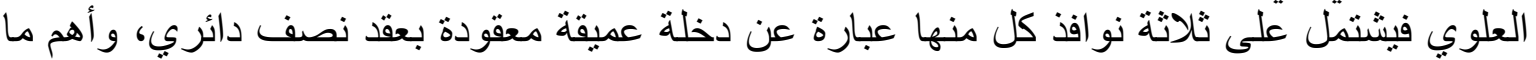

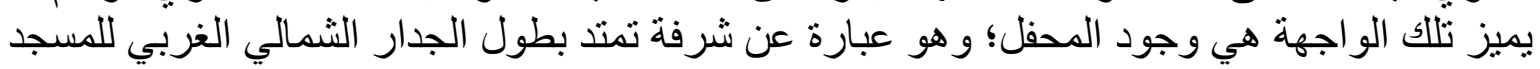

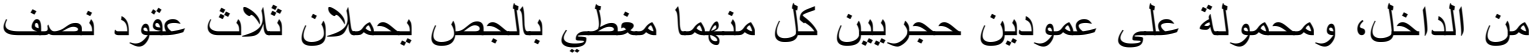

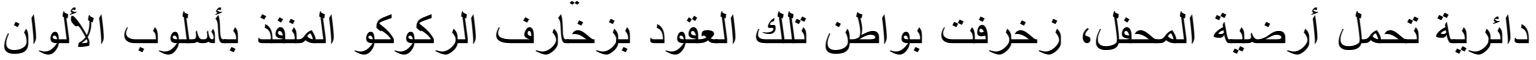
المائية على الجص، و الثرفة محاطة من أعلي بسياج خشبي، و أرضيتها أيضا مصنو عة من الخشب.

الجدار الثمالي الثرقي للمسجد من الداخل يشتمل علي شباكين سفليين كل منهما عبارة عن فتحة مستطيلة غائرة، أما المستوي العلوي فيشمل نافذتين غائرتين و عميقتين معقودنين بعقود نصف دائرين

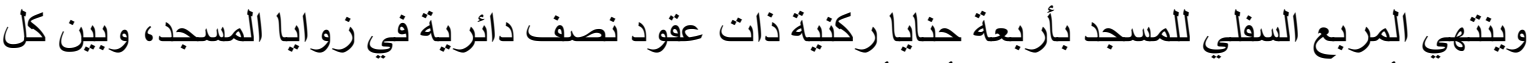

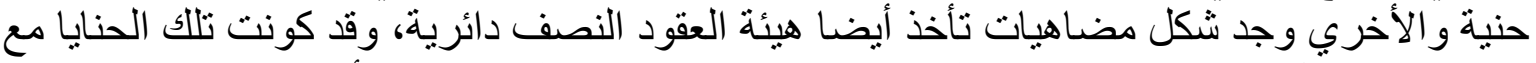

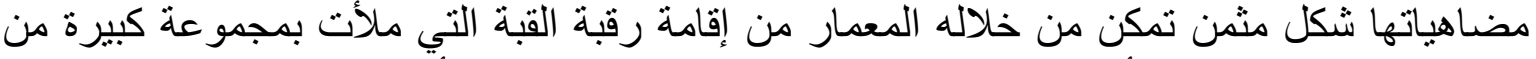

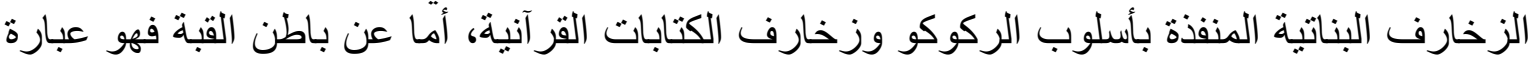

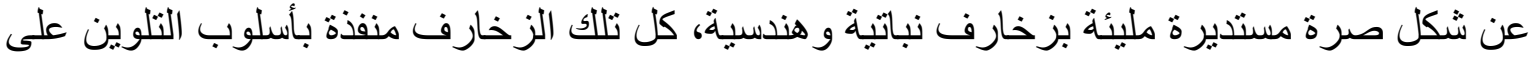

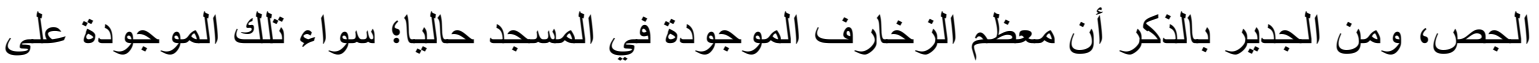
القبة أو التى تزين الأعمدة ترجع إلي أعمال البناء الأخيرة التي تمت على على المسجده 


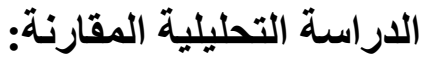

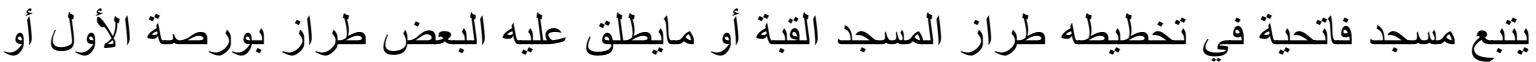

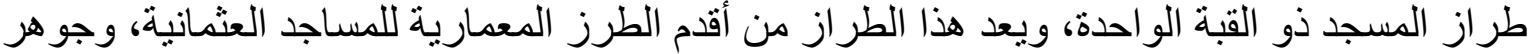

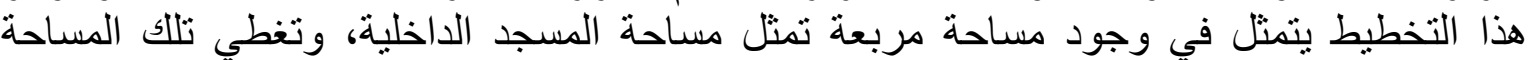

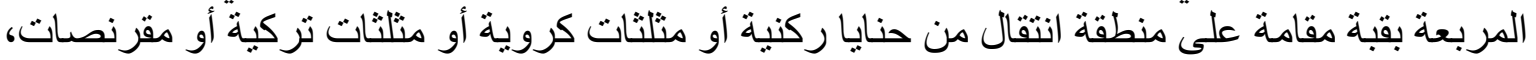
وفي أغلب الأحيان يتقام المساحة المربعة للمسجد رواق خارجي مغطي إما بقباب أو أقبية أو سقف مائلّ. بو

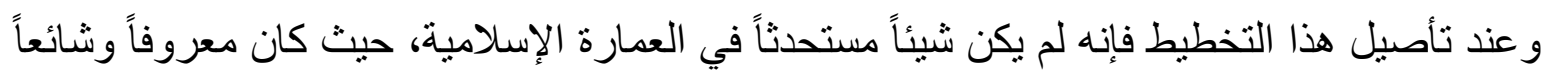

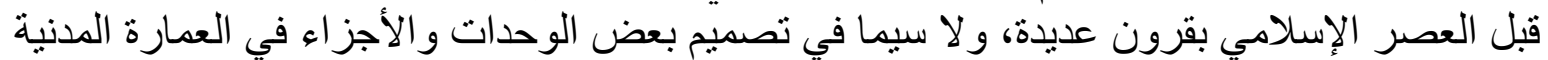

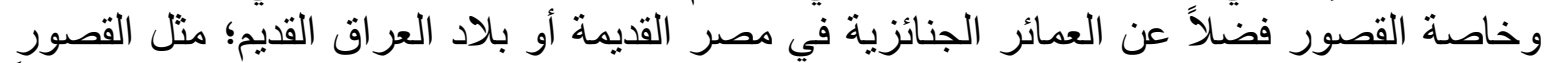
الساسانية القديمة وفي جبانة البجو ات بالداخلة في محافظة الو ادى الجديد، وقد ظل هذا لإدا التخطيط باقياً

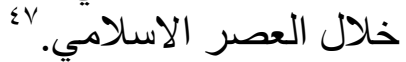

أما عن إستخدام هذا النمط في تخطيط المساجد فقد كان قديما وأول إنشار ات واضحة على إلى إستخدامه في

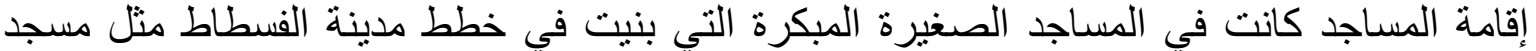

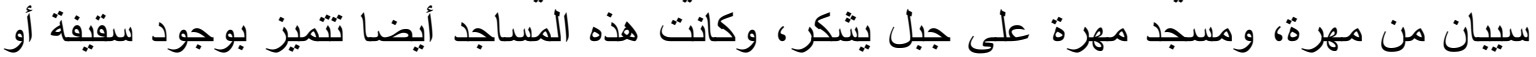

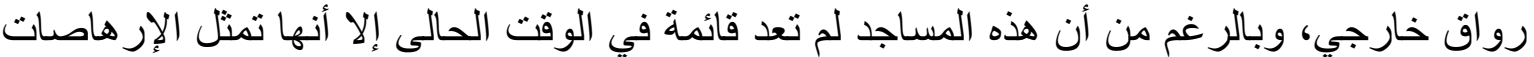

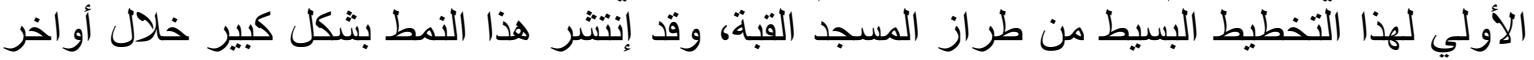

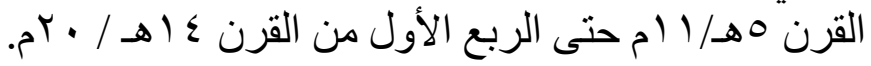

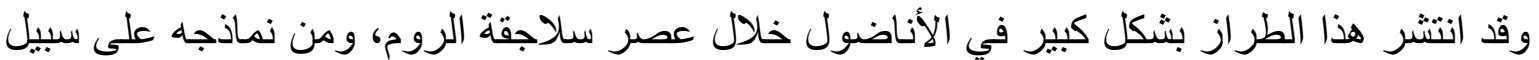

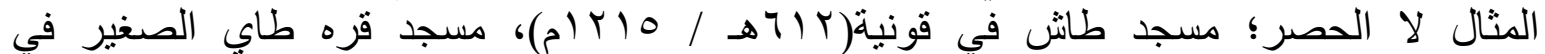

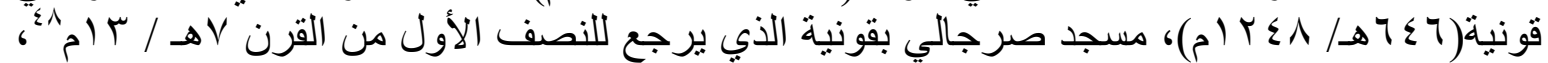

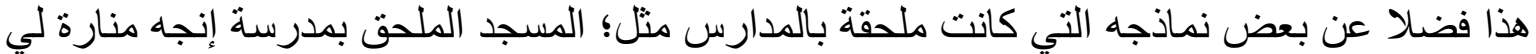

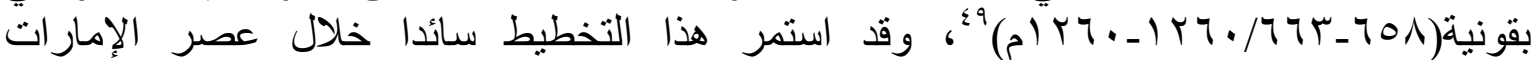

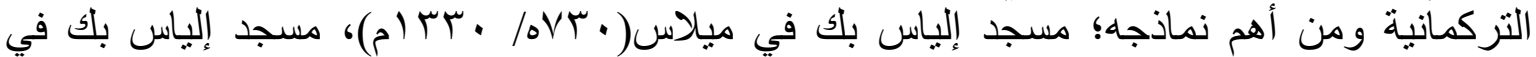

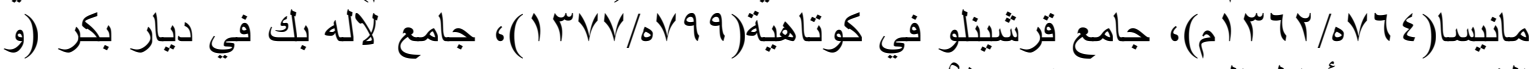

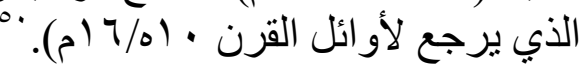




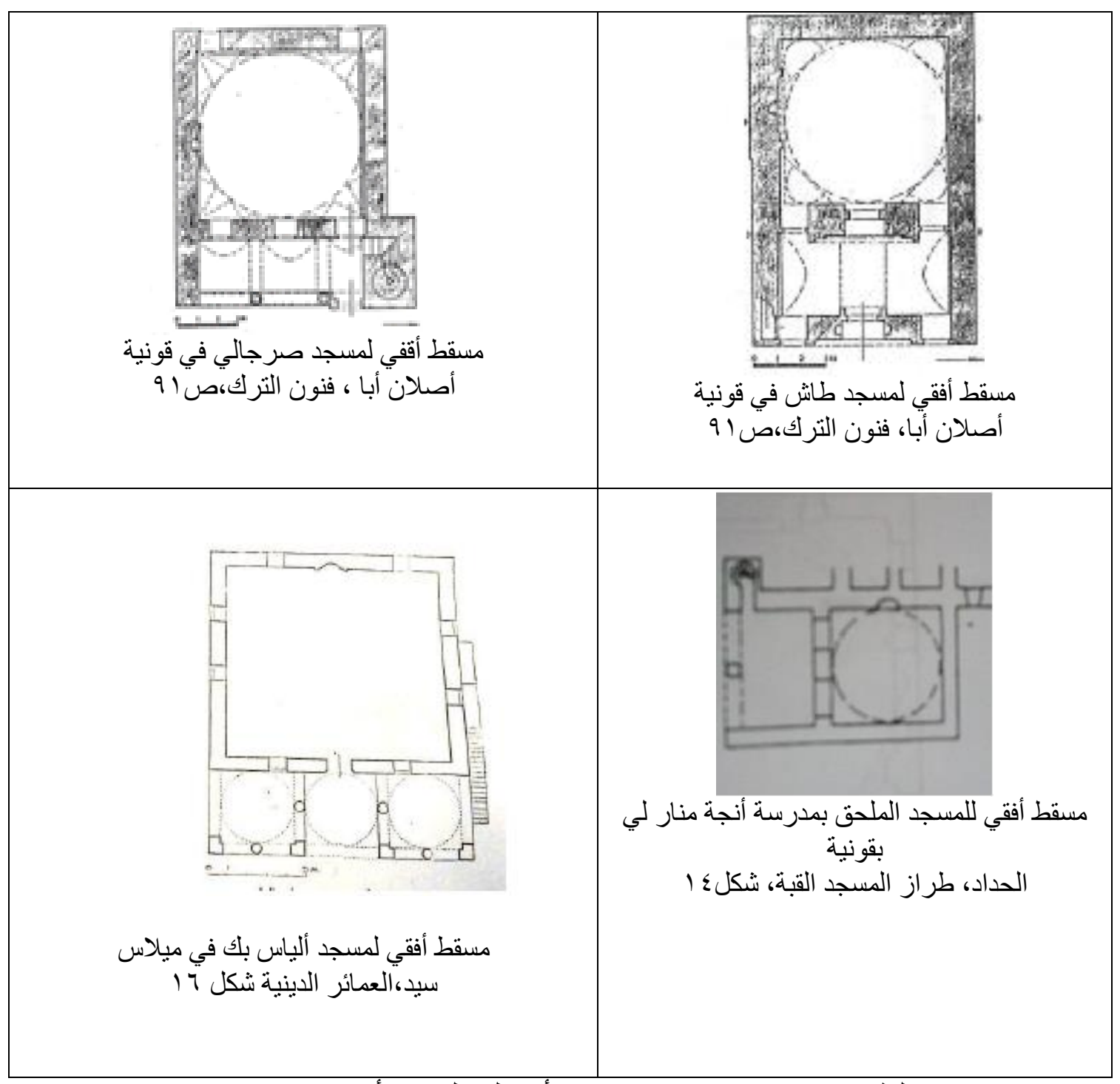

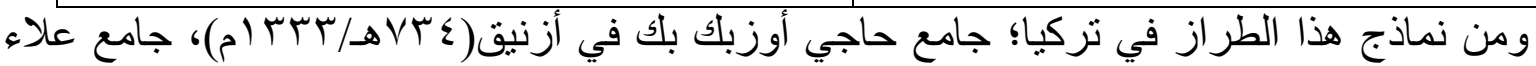

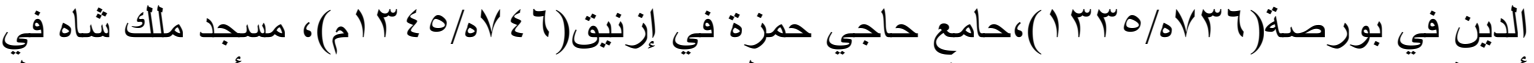

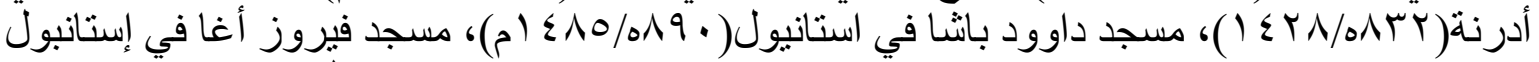

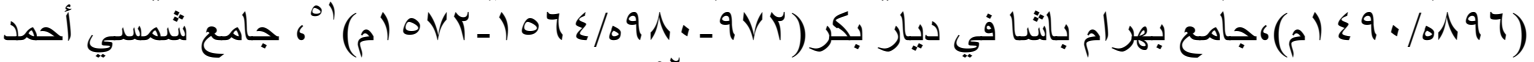

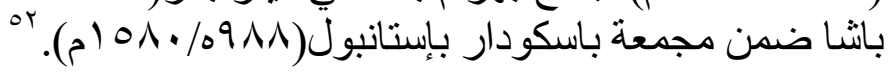




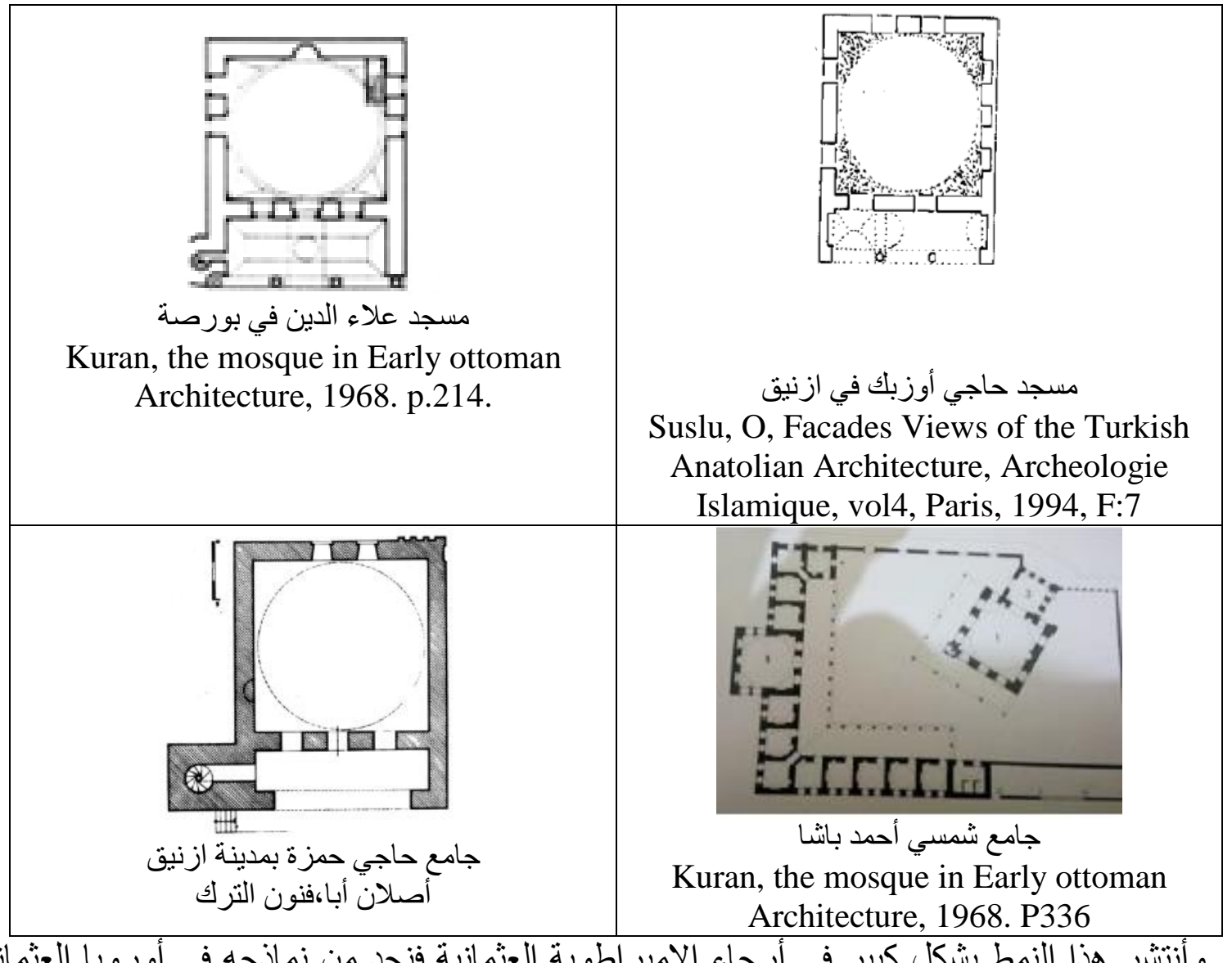

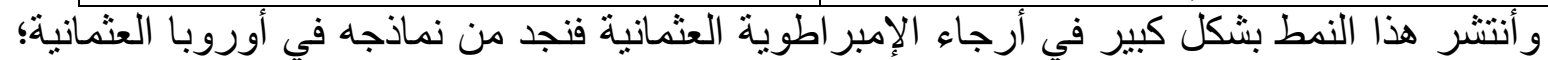

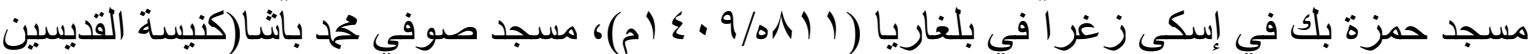

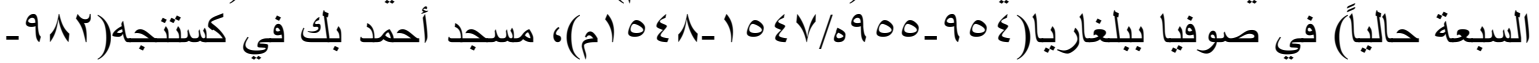

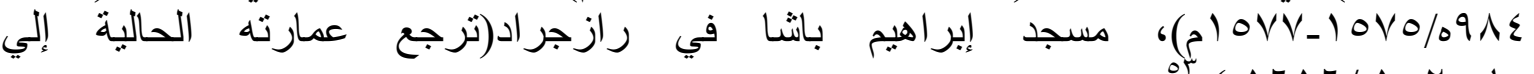

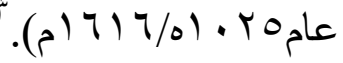

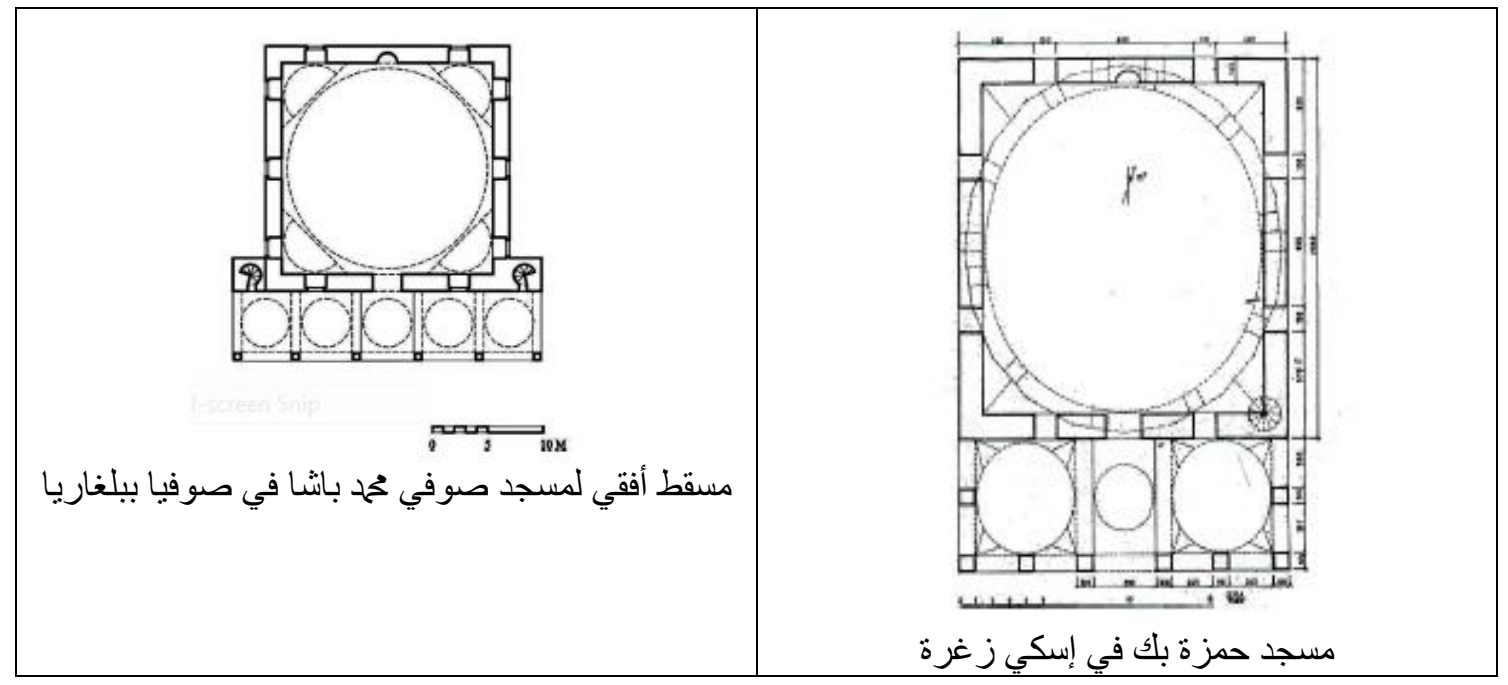




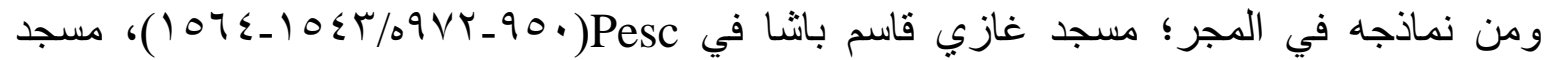
ملكوش بك في Siklos

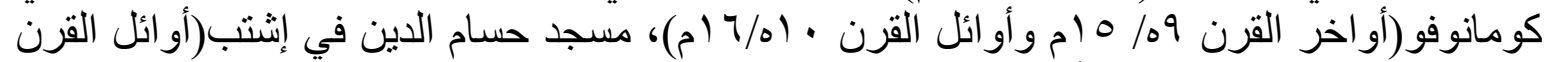

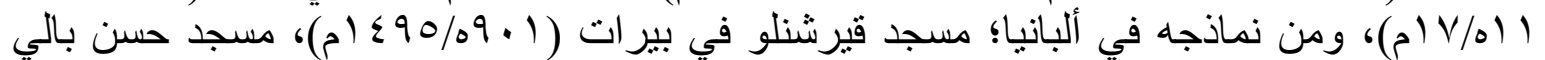

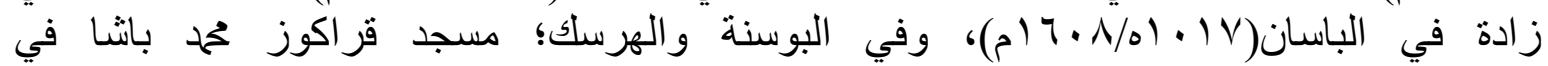

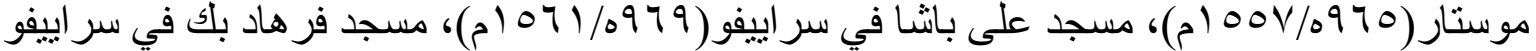

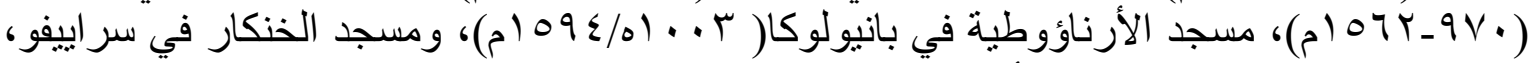

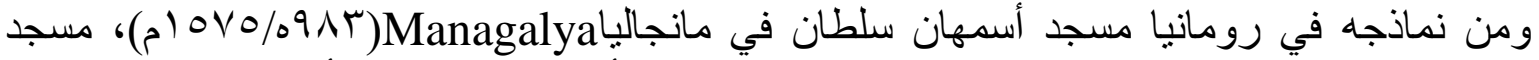

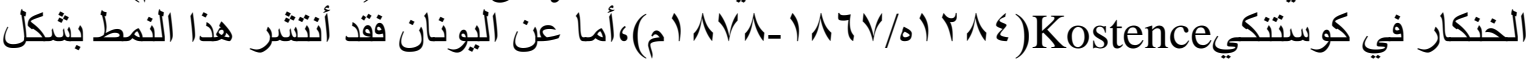

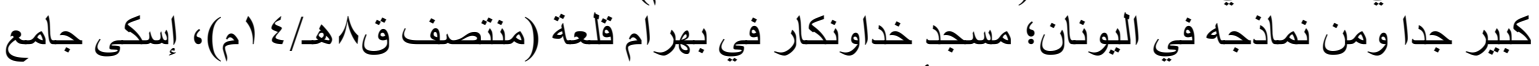

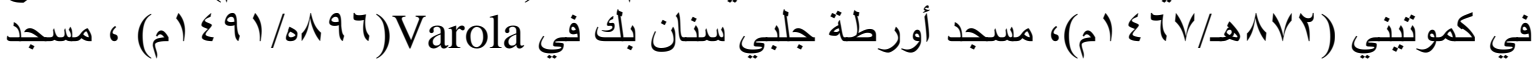

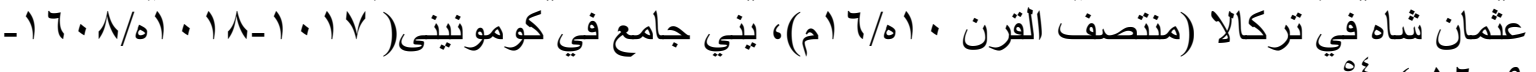
0 . (م) 7 (م)

\begin{tabular}{|c|c|}
\hline مسجد الأرناؤوطية في بانيالوكا بالبوسنة والهرسك Ayverdi,Avrupa,s15 & $\begin{array}{c}\text { جامع الخنكار بسر اييفو } \\
\text { Ayverdi,Avrupa,s359,360 }\end{array}$ \\
\hline Ameen,Islamic Architecture, p172 & 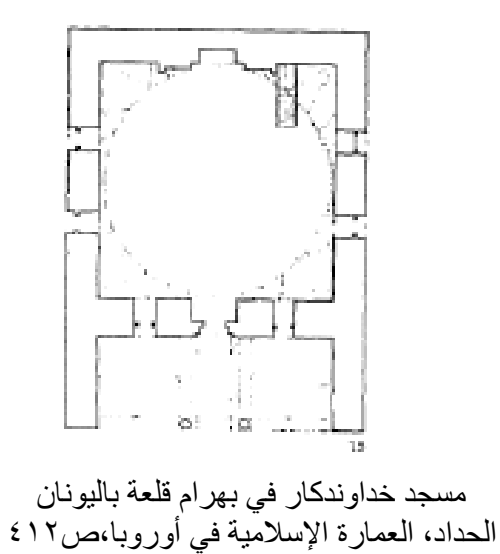 \\
\hline مسجد أورطة جلبي سنان بك في Architecture, p111 & ينى جامع في كوميتينى \\
\hline
\end{tabular}




\section{الخاتمة ونتائج البحث :}

- يعد مسجد فاتحية الواقع في مدينة يانيه "يانينا" بشمال اليونان واحد من بين أربع مساجد فقط ماز الت باقية في تللك المدينة حتى الأن.

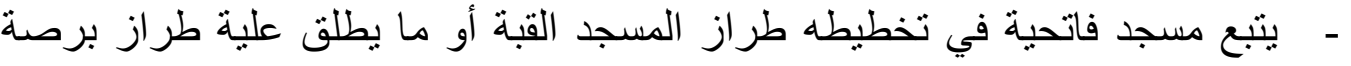

- يتميز مسجد فاتحية بظاهرة تعدد المحاريب حيث يوجد محراب أساسي في المسجد من الداخل بالإضافة لمحر اب أخر موجود في الواجهة الثمالى الغربي للمسجد.

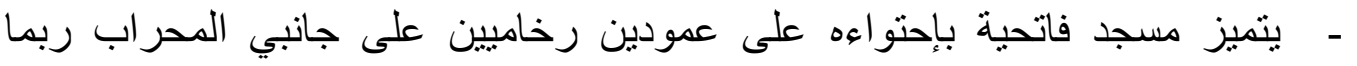
يعودان إلى أنقاض البناء السابق عليه في نفس الموقع. باحتو - يتميز محراب مسجد فاتحية بالكثير من الرسومات الملونة المنفذة بلألوان المائية، و المنفذة بأسلوب الركوكو. مجراب 


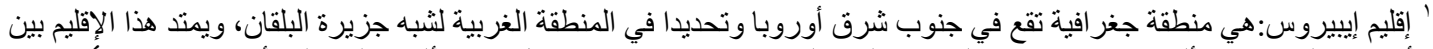

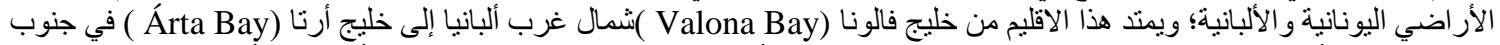

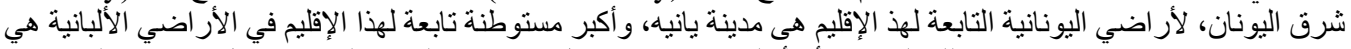

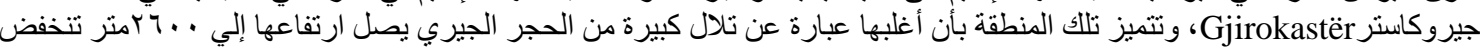
ت تلك الجبال بثدة في إتجاه الغرب.

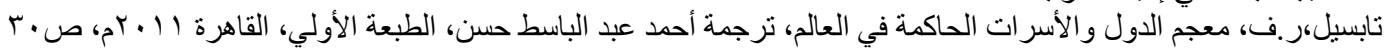
https://www.britannica.com/place/Epirus

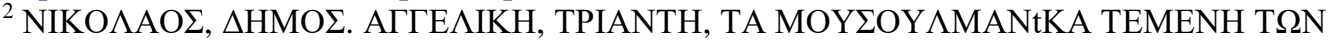

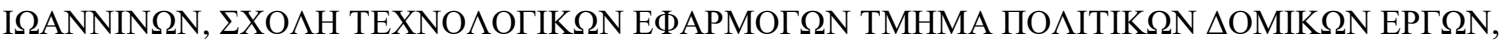
IANOYPIO $\Sigma 2003, \sigma \varepsilon \lambda 5$

${ }^{3}$ ISLÂM ANSIKLOPEDISI , TÜRKIYE DIYANET VAKFI , CILT 43, Istanbul 1996,ss317-321

${ }^{4}$ The Encyclopaedia of Islam,New Edition, Vol XI,Brill Leiden 2002,p282

${ }_{6}^{5}$ Leak,Willian Martin, Travels in Northern Greece, J.Rodwell,1835,p405

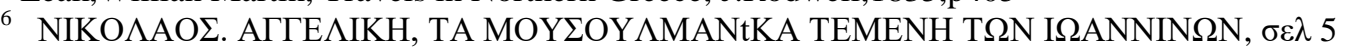

${ }^{7}$ Spanou,Sofia Maria,Worled Heritage List:The Castle of Ioannina, Master of Art (MA)in Art Low and Economy ,International Hellenic University,Thessaloniki-Greece,January 2016,p19

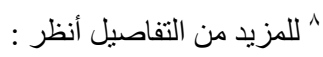

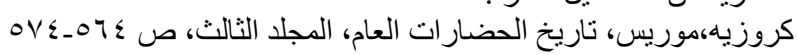

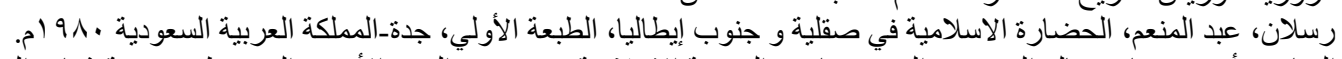

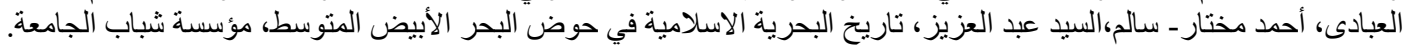

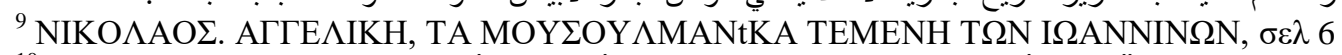

${ }^{10}$ NURJA, ERMAL, YANYA VILAAYETI AMED-REFT DEFTERLERINE GÖRE YANYA'DA DINII

KURUMLAR, YAPILAR VE DINII HAYAT,s5

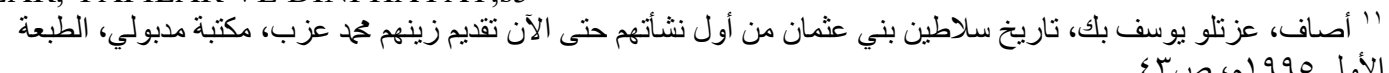

${ }^{12}$ KILIÇ ,Ayşegül ,Yanya'da İlk Osmanli Hâkımıyet Dönemı ve XIV.Yüzyila Aıt Unutulmuş Bır

Zâviye,Balkan Araştirma Enstitüsü Dergisi,Cilt 5, Sayı 1, Temmuz 2016 ,s148

${ }^{13}$ Spanou,Sofia Maria,Worled Heritage List:The Castle of Ioannina ,p19

${ }^{14}$ Ameen,Ahmed, OTTOMAN USE OF EXISTING PUBLIC BUILDINGS IN FORMER B YZANTINE

TOWNS: GREECE AS A CASE STUDY, 15th International Congress of Turkish Art, Naples, Università di Napoli “L'Orientale" 16-18 September 2015, Ankara 2018 ,p95

${ }^{15}$ The Encyclopaedia of Islam,p282

${ }^{16}$ ÖZTUĞ, YANYA MERKEZ OSMANLI MIMARİSI, YÜKSEK LİSANS TEZİ SANAT TARİHİ ANA

BILIMM DALI, ANKARA HACI BAYRAM VELİ ÜNIVERSITESİ LISSANSÜSTÜ EĞITIIM ENSTITTÜSÜ,

EYLÜL 2019 ,s11

${ }^{17}$ Spanou,Sofia Maria,Worled Heritage List:The Castle of Ioannina ,p19

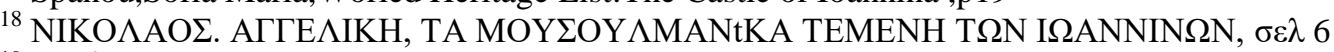

${ }^{19}$ ISLÂM ANSIKLOPEDISI,ss317-321

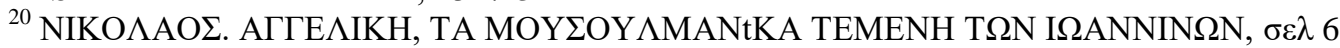

${ }^{21}$ The Encyclopaedia of Islam,p282

${ }^{22}$ Doempke,Stephan,Coca,Anduela Lulo,Petrela,Sadl, Four Historic Cities In The Western Balkans, Tirana 2012,p78

${ }^{23}$ ISLÂM ANSIKLOPEDISI, ss $401-402$

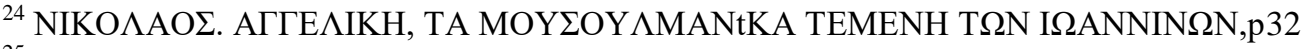

${ }^{25}$ Spanou,Sofia Maria,Worled Heritage List:The Castle of Ioannina ,p22

${ }^{26}$ Ottoman Architecture IN Greece, Hellenic Ministry of Culture - Directorate of Byzantine and Post Byzantine Antiquities ,p162

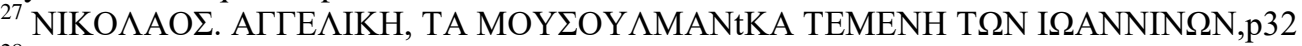

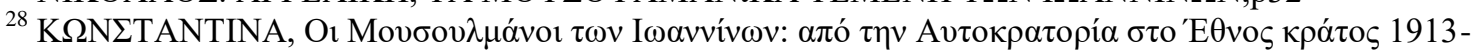
$1923, \sigma \varepsilon \lambda 92$

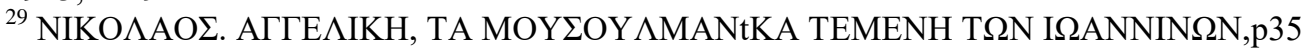

ÖZTUĞ, YANYA MERKEZ OSMANLI MIMARİSİ,s105

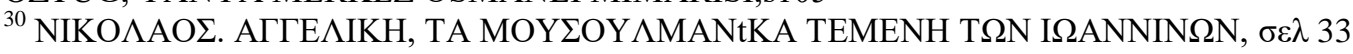


${ }^{31}$ ESCUTIS, Elevating and Safeguarding Culture Using Tools of the Information Society: Dusty traces of the Muslim culture: The Muslim Presence in Epirus and Western Greece, University of Cyprus ,Nicosia, Cyprus,P381

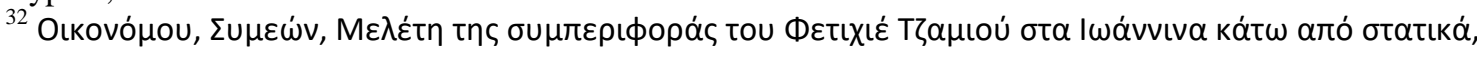

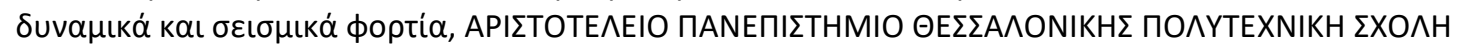

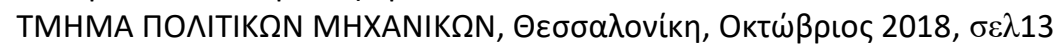

${ }^{33}$ Spanou,Sofia Maria,Worled Heritage List:The Castle of Ioannina,p23

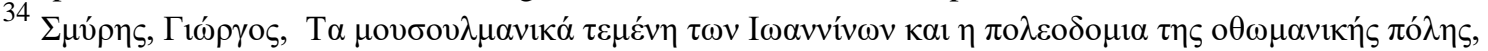

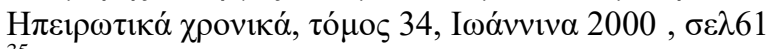

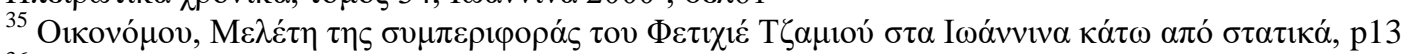

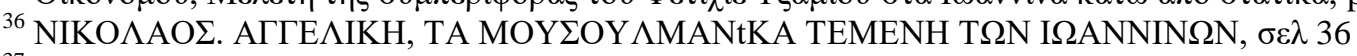

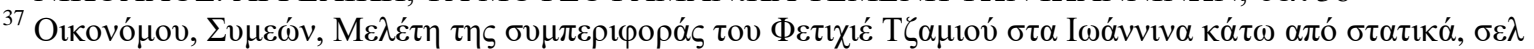
28

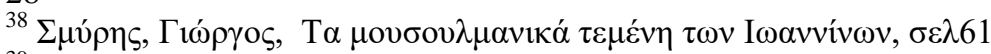

${ }^{39}$ Spanou,Sofia Maria,Worled Heritage List:The Castle of Ioannina, $\sigma \varepsilon \lambda 23$

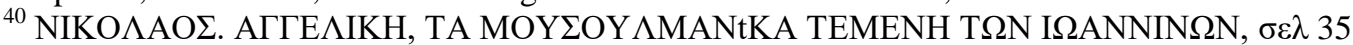

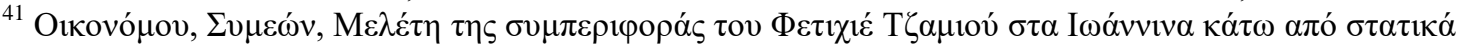
$\sigma \varepsilon \lambda, 28$

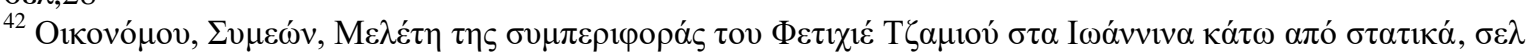
13

بَّتلك الزخارف الممثلة في ظهور أنماط جديدة من أثكال نباتية وهندسية تشير الي الحركة الفنية الجديدة التي كانت سائدة في تلك الفترة التى التى تأثرت بالتأكيد بالمشاركة مع التقافات المختلفة في المنطقة في أو اخر العند العصر العثماني.

Spanou,Sofia Maria,Worled Heritage List:The Castle of Ioannina 2016,p23

${ }^{44}$ Doempke,Stephan,Coca,Anduela Lulo,Petrela,Sadl,p85

${ }^{45}$ Ottoman Architecture IN Greece, Hellenic Ministry of Culture,p162

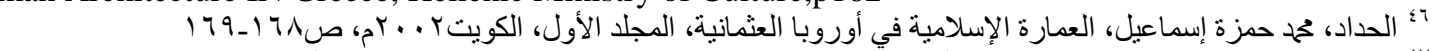

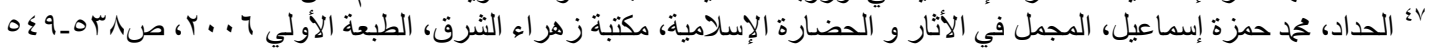

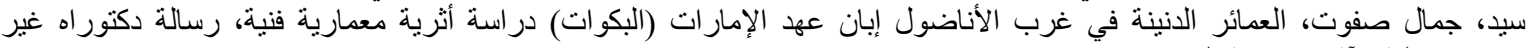

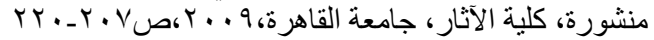

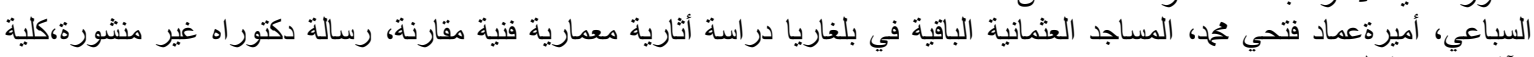

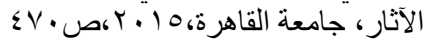

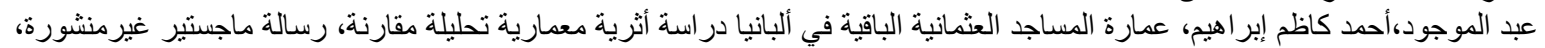

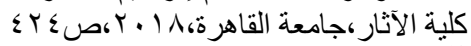

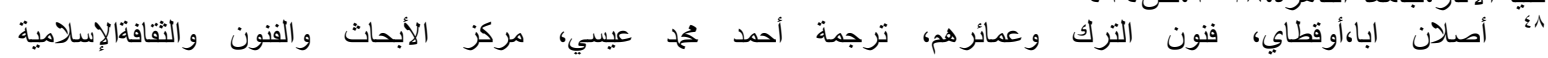

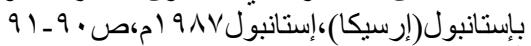

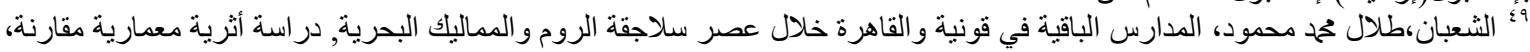

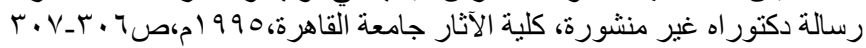

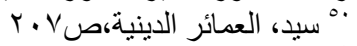

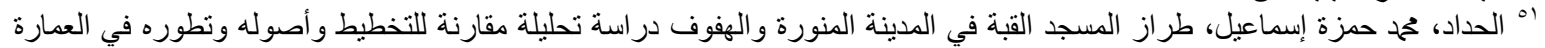

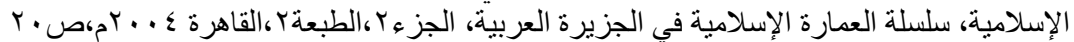

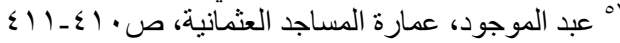

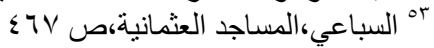

${ }^{54}$ Ameen, Ahmed, Islamic Architecture In Greece :Mosques, Bibliotheca Alexandrina, Center for Islamic Civilization Studies, 2017,pp110-115,154-159,171-177 